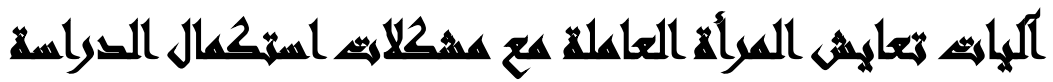

[11]

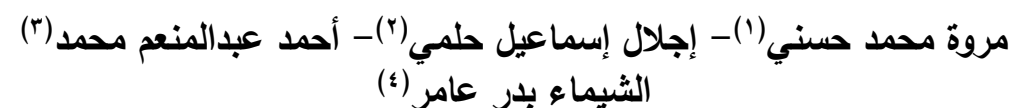

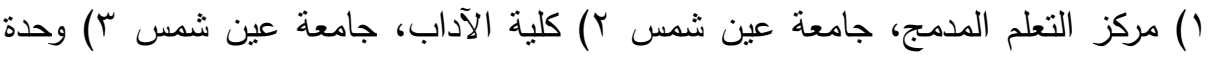

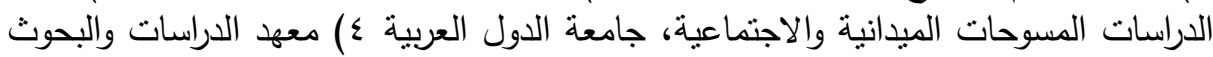
البيئية، جامعة عين شمس المس البن

\section{المستخلئ}

هدفت الدراسة إلى التعرف على المشكلات التى تواجه المرأة العاملة في حالة استكمال

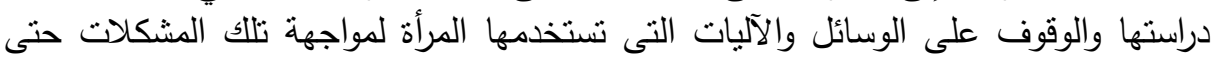

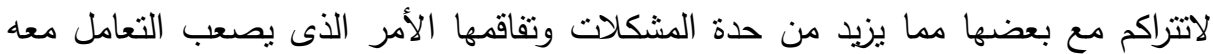

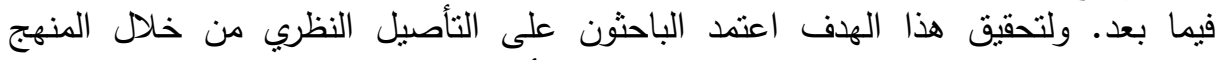

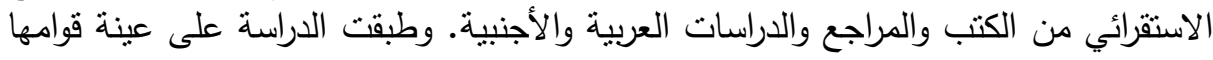

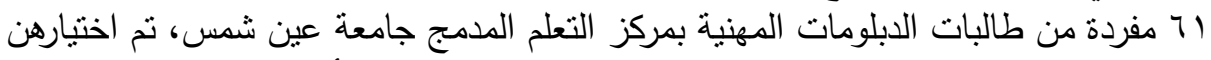

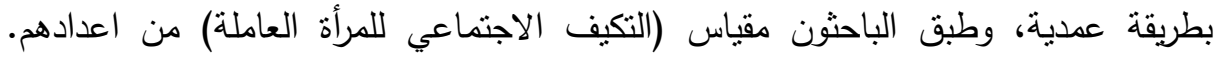

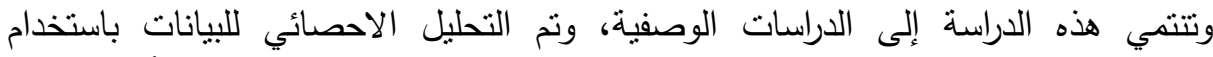

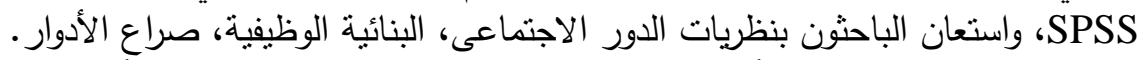

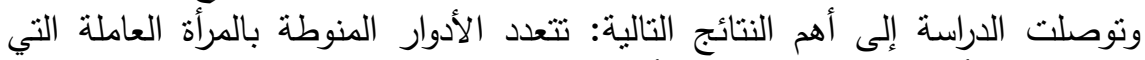

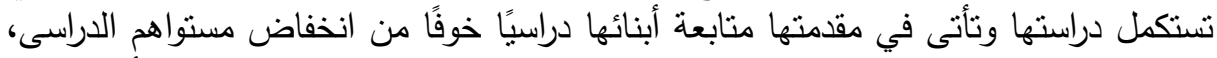

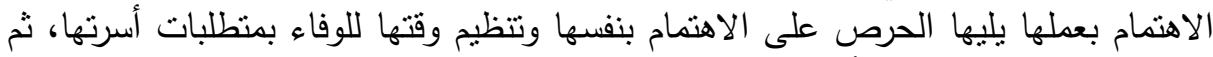

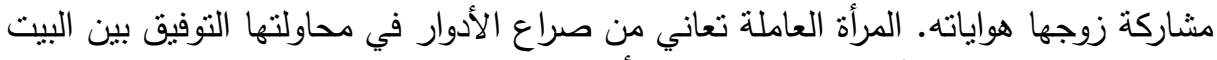

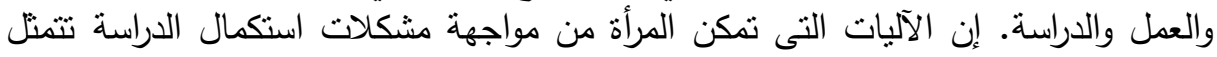

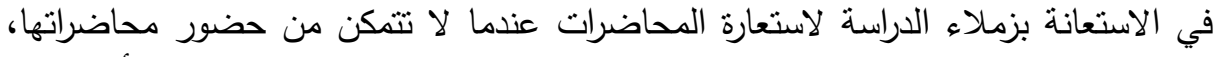

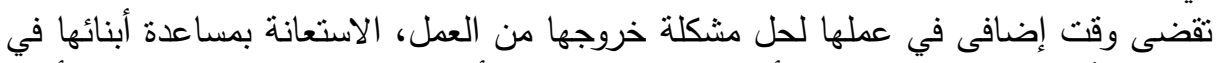

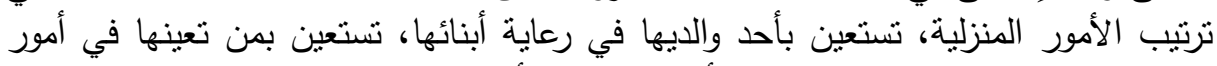

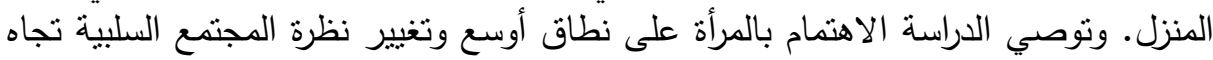

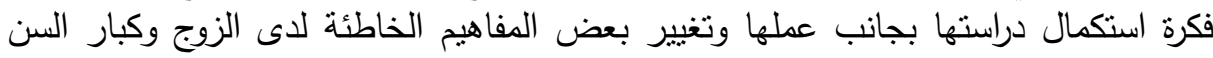




\section{المهنs}

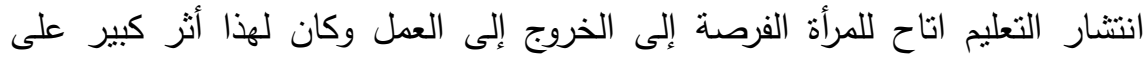

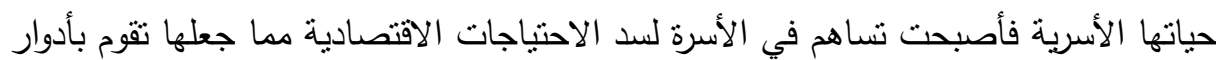

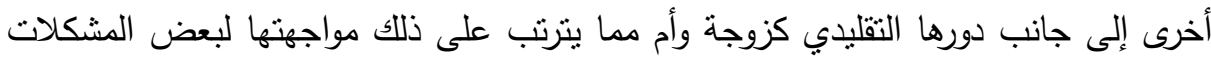

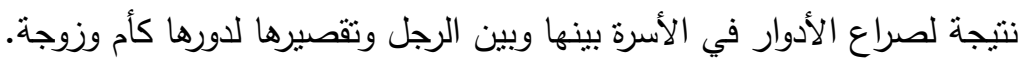

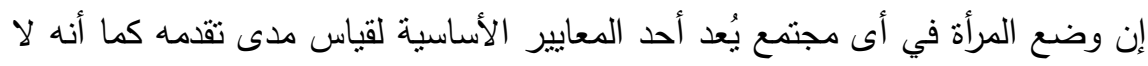

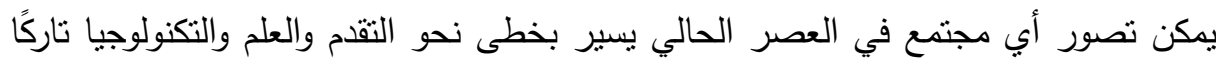

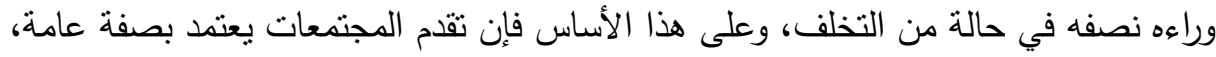

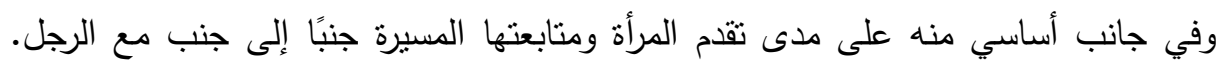

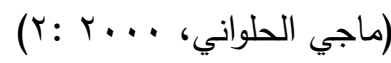

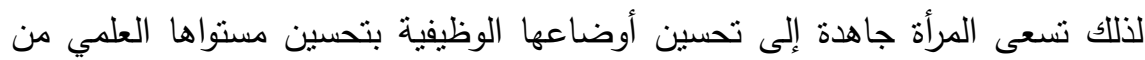

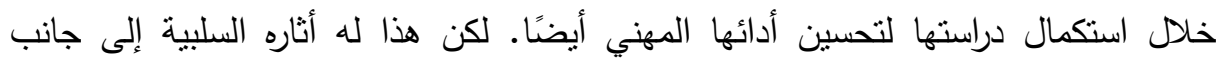

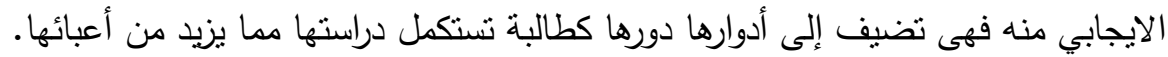

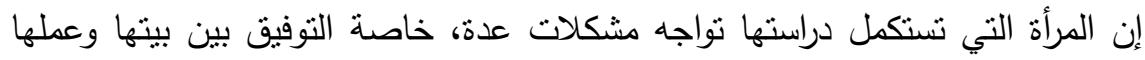

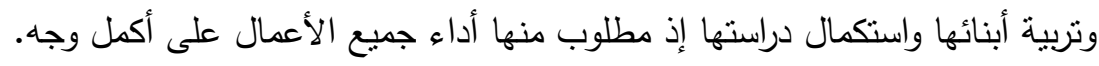

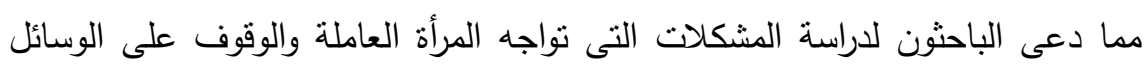

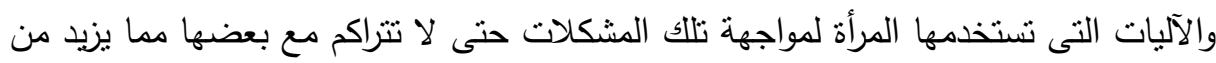

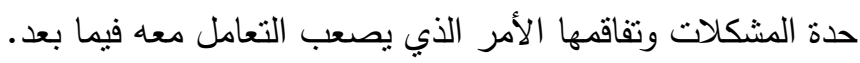



بعد الإطلاع على العديد من الدراسات السابقة ومنها دراسة (داليا محمد عمارة،

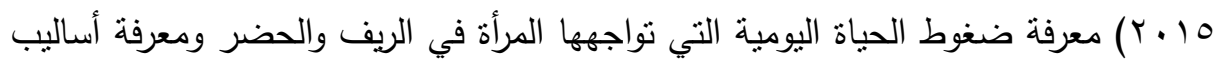

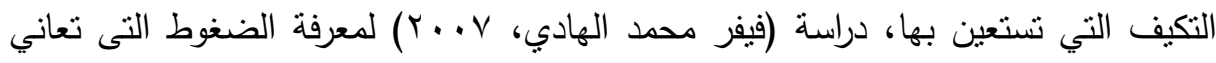

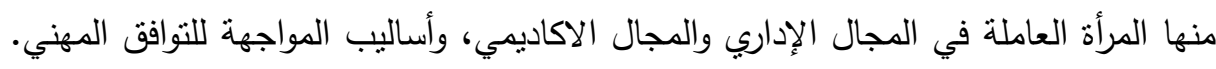
نجد إن المرأة تلجأ إلى العديد من الآليات والأساليب التي تجعلها مستقرة ومتوازنه نفسيًا 
واجتماعيًا في حياتها الوظيفية والأسرية فهى نستخدم هذه الأساليب يوميًا بشكل دائم لمواجهة

$$
\text { المشكلات اليومية التى تتعرض لها. }
$$

فعليها التوفيق بين أدوارها التى تتمنل في دورها الوظيفي ودورها في المنزل كزوجة،

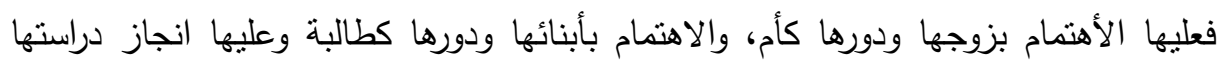
بالاضافة إلى واجباتها المنزلية، وبجانب ذللك عليها الاهتمام بنفسها لذلك فعليها ودهام استخدام الأساليب المختلفة لمواجهة هذه التحديات. وهذا ما تسعى إليه الباحثة لدراسته.

\section{تماولاهت اللهمهث}

ا. ـ ما الأدوار التى تقوم بها المرأة العاملة التى تستكمل دراستها؟

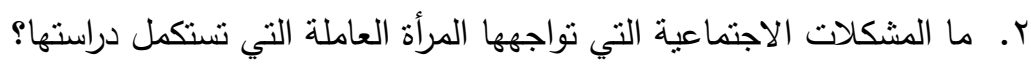

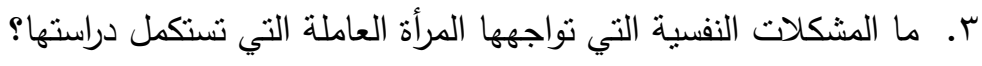


๑. هل تختلف الآليات المستخدمة لدى المرأة حسب المتغيرات التالية: السن، الحالة الاجتماعية، الوظيفة؟

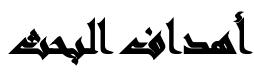

( ) رصد الأدوار المتعددة للمرأة العاملة التى تستكمل دراستها.

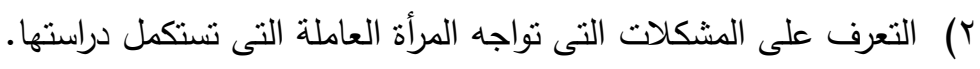

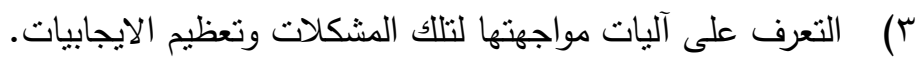

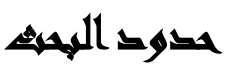

طبقت الدراسة على طالبات الدبلومات المهنية بمركز التعلم المدمج بجامعة عين شمس.

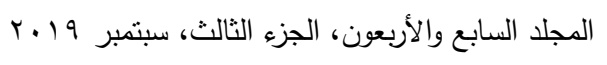




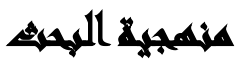

المنهج الوصفي التحليلي: ويُعد من طرق التحليل والتفسير بشكل علمى للوصول إلى أسباب المشكلة ويهنم بوصفها وصفًا دقيقًا.

\section{أهمية الهميث}

الأهمية النظرية: إثراء الدراسات السوسيولوجية المرتبطة بموضوع الدراسة (آليات تعايش المرأة العاملة مع مشكلات استكمال الدراسة) مع إثراء المداخل النظرية المرتبطة به. الأهمية التطبيقية: تحديد أهم المشكلات الاجتماعية والاقتصادية والنفسية التى تعانى منها المرأة الراغبة في استكمال دراستها للابلومات المهنية، و التحديات التى نواجهها والتى تعيقها

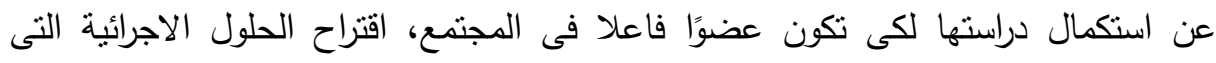

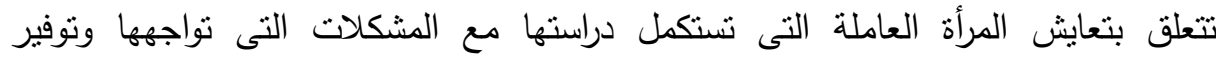
الخدمات التى تساعد المرأة العاملة التى تستكمل دراستها حتى تسنطيع التوفيق بين بيتها

$$
\text { وعملها ودراستها. }
$$

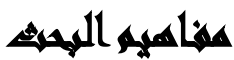

المشكلة الاجتماعية: موقف غامض ومسألة لم يسبق للفرد التعرض لها ولا يعرف كيفية حلها مما يستدعى لديه القيام بمجموعة من العمليات اللازمة لتخطى العائق والوصول إلى لى لهي

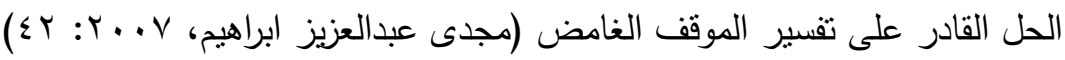
آليات التعايش: تشير إلى الطريقة التى تُؤدى بها الأشباء أو إلى الأساليب والإجراءات

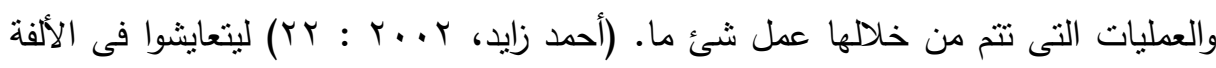

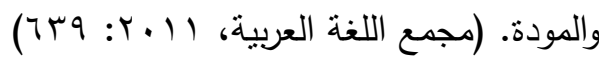
المرأة العاملة: هى التى تقوم ببذل مجهود ذهنى أو عضلى أو الأثثين معًا فى العملية

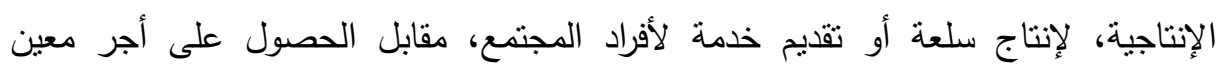


تستخدمه فى إثباع حاجاتها وحاجات أفراد الأسرة. (محمد عبد الستار عبد المجيد: 9 . ؟r،

الاور: هو مجموعة من السلوكيات التى نتوقعها من شخص ما فى موقع أو موقف معين.

(Holiander, E. P.:1978,)

\section{الصراسايت المايرية}

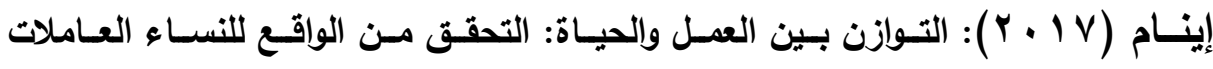
في بنغلاديش.

Tasnim, M.; Hossain, M. Z. and Enam, F. (2017): Work-Life Balance: Reality Check for Working Women of Bangladesh. Journal of Human Resource

هدفت الدراسة إلى معرفة الأسباب التى تخلق خلاً في التوازن بين العمل والحياة، ونظرًا إلى أن النساء العاملات تواجه في بنغلاديش صعوبات أكبر في تحقيق التوازن بين العمل والحياة مقارنة بالموظفين الذكور، فإن هذه الدراسة تركز على النساء العاملات في مختلف القطاعات. وقد طبقت الدراسة على عينة من ·ـ موظفة من مختلف المنظمات. واستخدمت الدراسة استمارة استنيان والمقابلات الثخصية. وتوصلت الدراسة: إلى زيادة عبء العمل والمسئوليات المتعلقة برعاية الطفل والتمييز

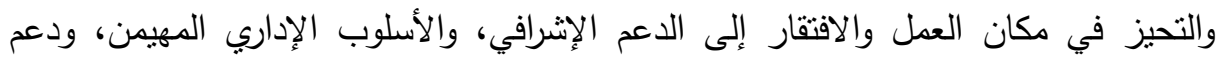

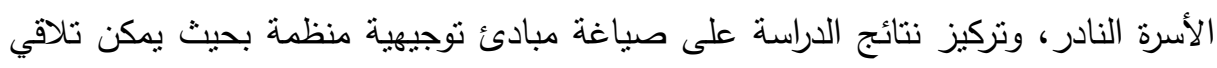
الضغوط بحيث يمكن للموظفات الموازنة بين حياتهن المهنية والثخصية والعيش في وئئام. 
داليا محمد أحمد عمارة (10 ب ب): ضغوط الحياة اليومية على المرأة وأثرها على التكيف البيئي - دراسة ميدانية فى بيئة حضرية وأخرى ريفية.

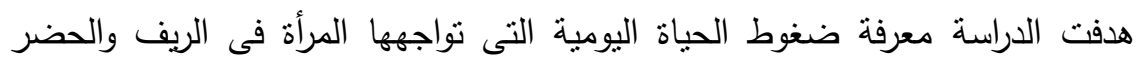

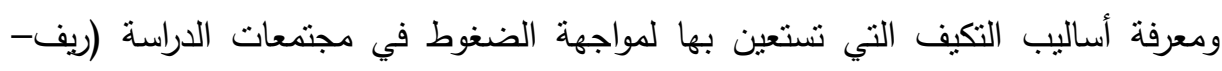

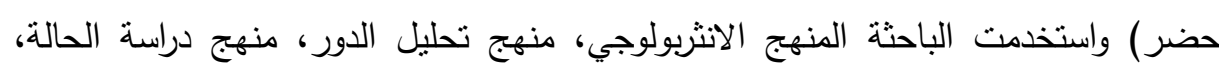

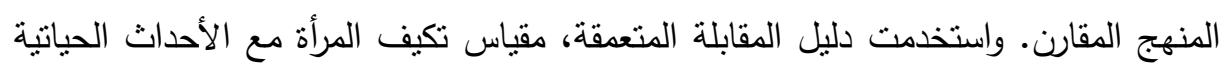

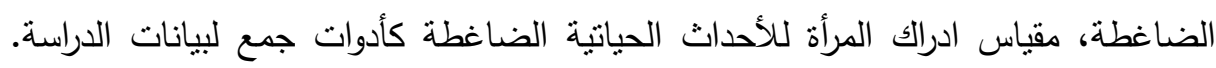
وطبقت الدراسة على عينة مكونة من . ب مفردة من النساء.

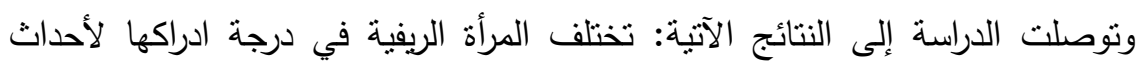

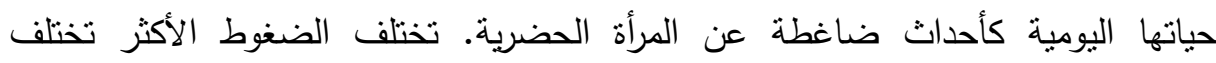

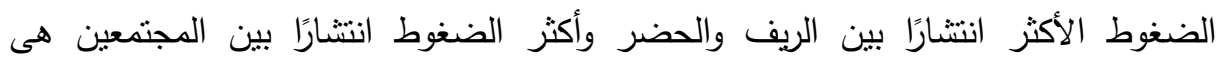

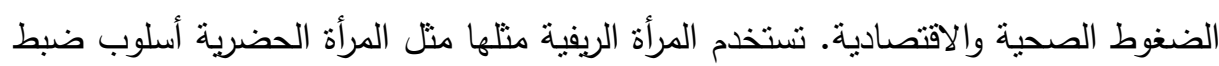
النفس للتكيف مع ضغوط الحياة وتختلف عنها في استخدامها لبقية الأساليب.

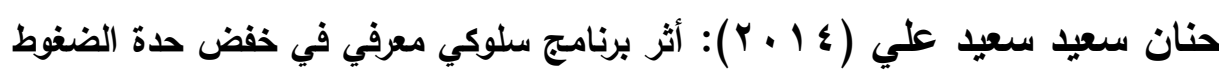
النفسية الواقعة على المرأة العاملة.

تهدف الدراسة إلى التعرف على أثز برنامج عقلانى إنفعالى سلوكي معرفي في خفض العضاف

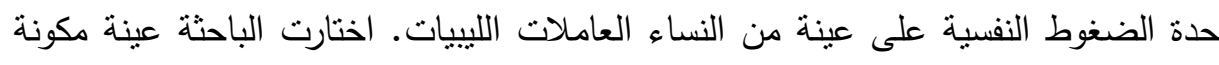

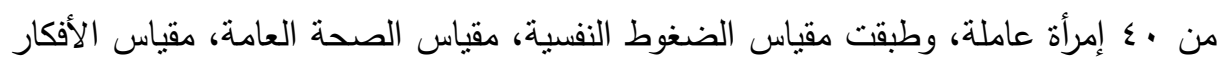
العقلانية واللاعقلانية. وتوصلت الدراسة: أنه يوجد إرتباط موجب بين الضغوط النفسية والقلق والإكتئاب،

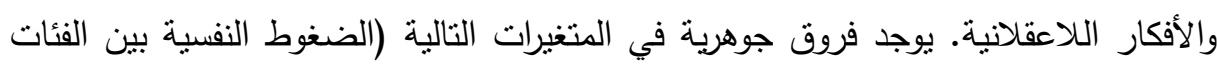

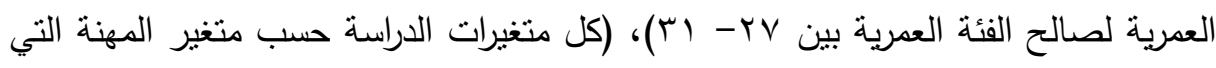



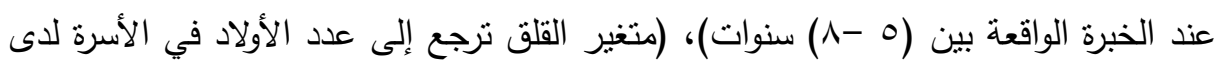

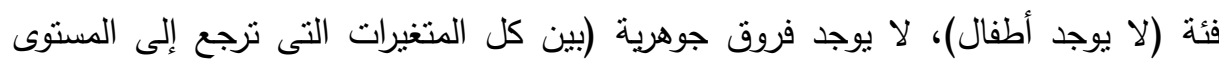
242

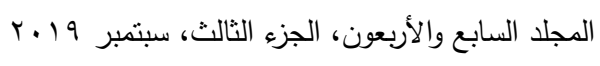


الدراسي)، (بين المجموعتين التجريبية والضابطة في القياس القبلي)، (في القياس البعدي بين مجموعتي البرنامج بالنسبة للمتغيرات فيما عدا متغير الضغوط النفسية)، (بين القياس البعدي والقياس التتبعي فيما عدا متغيري الضغوط النفسية والأفكار اللاعقلانية)، ثبت فاعلية البرنامج الانفعالي السلوكي المعرفي.

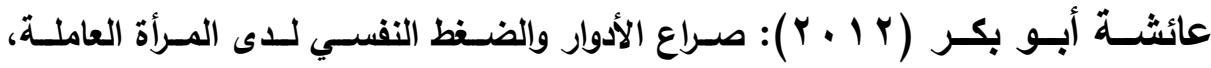
دراسة ميدانية على مجموعة من المعلمات بولاية ميلة بالجزائر .

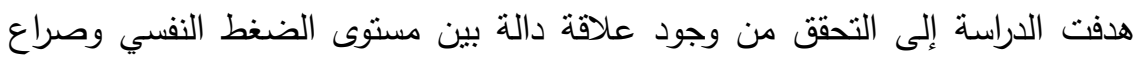

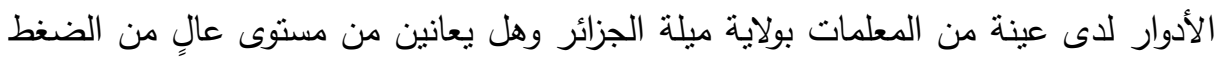

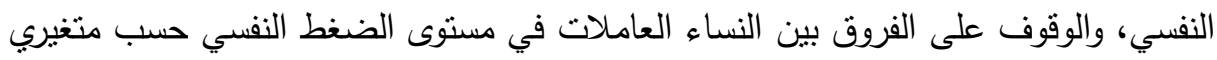
عدد أبناء كل امرأة عاملة وكذلك سنوات الخبرة في العمل. واستخدت الدراسة المنهج الوصفي. وطبقت الدراسة على عينة مكونة من • ب معلمة متزوجات ولهن أبناء، وتم تطبيق مقياسين

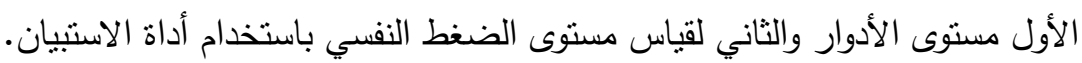
وتوصلت الدراسة إلى النتائج الآتية: نواجد المرأة في مختلف قطاعاتئ بات العمل بشكل إيجابي كمساهمتها في بناء المجتمع وتتميته وإحساسها بقيمة إنجازتها وعطائها وكذا دعمها

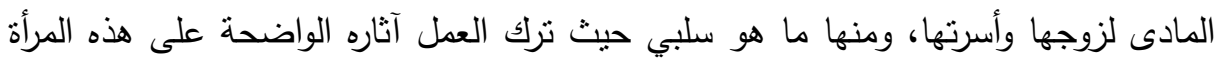
العاملة، والذي يتجلى بشكل بارز في تعدد أدوارها وتكاثف واجباتها، وتتوع مسئولياتها وبالتالي

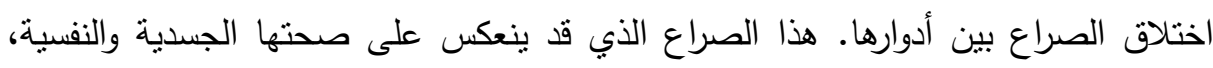

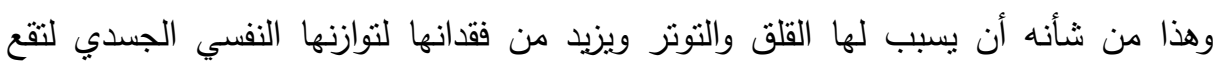

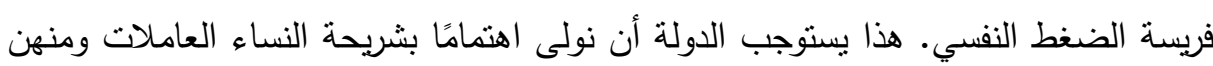
العاملات باعتبارهن عرضة لجملة من المشاكل والاضطرابات التي تتجم عن الأسرة أو العمل. 
بوت ودافيد جونسون والان بوث: أثر عمل المرأة خارج منزلها على استقرارها الزواجي. Alan Booth, Women outside Employment and Marital Instability, American Journal of aociology, volume go, No. 30, (1984).

هدفت الدراسة إلى رصد أثر عمل المرأة خارج منزلها على استقرارها الزواجي وأنَ نتائج

هذه الدراسة تدور حول ارتباط مدة الساعات التي تعملها الزوجة خارج المنزل مع ارتفاع دخلها

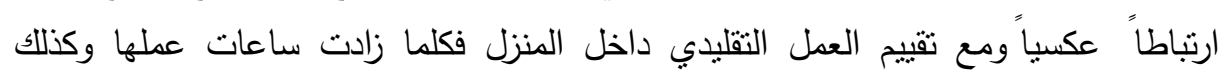
دخلها كلما قل اهنمامها بأدوارها التقليدية ومهامها المنزلية. تؤكد نتائج الدراسة على أهمية ساعات عمل المرأة خارج منزلها فعمل المرأة لمدة طويلة

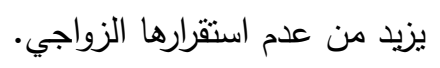

\section{الإسار المظلريه}

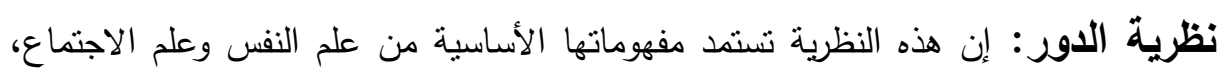

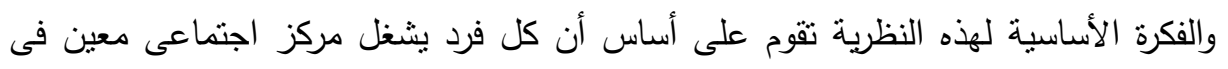

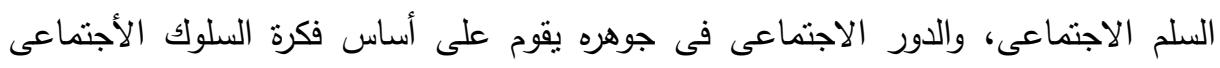

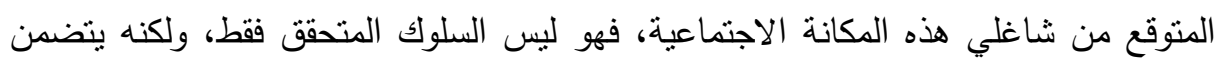

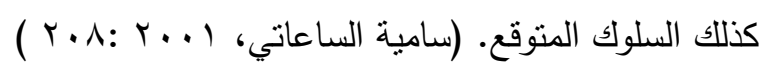
تفترض هذه النظرية أن جانبًا من السلوك البشرى ينسق ويأخذ شكلًا معينًا ليقابل التوقعات الاجتماعية المرتبطة بالمراكز والمكانات الاجتماعية التى يشغلها الأفراد في البنيان

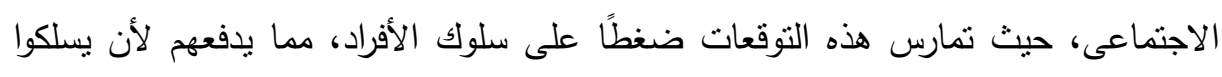


نظرية صراع الأدوار: إن تعارض التوقعات الخاصة بدور معين بالنسبة لثاغل مكانة

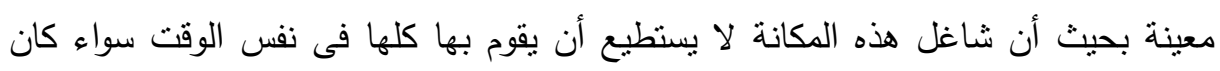

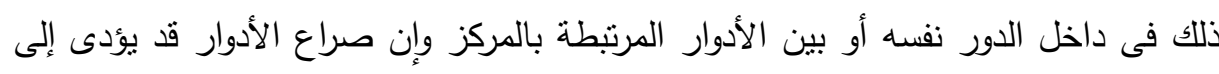

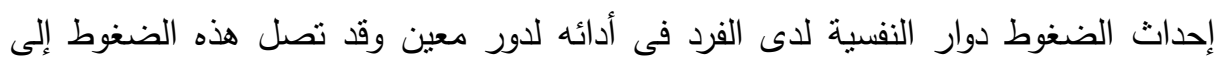

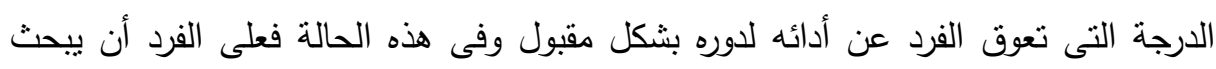


ويحاول حل هذه الصراعات بين الأدوار • (ابراهيم عبد الرحمن رجب، ب19 1: ـ ؟1) ويظهر

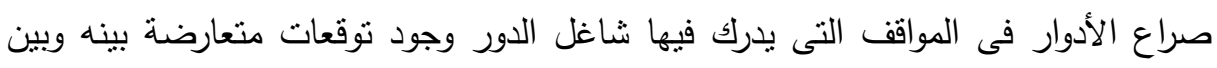

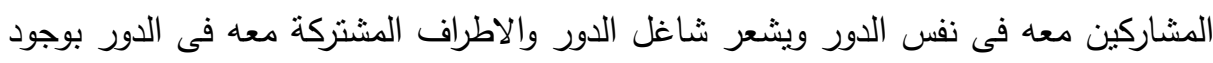

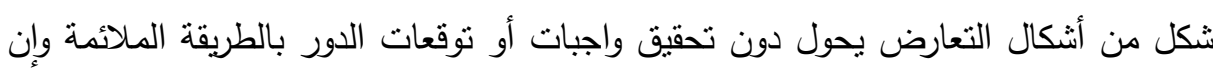
مصدر الصراع قد يحدث نتيجة للآتى:

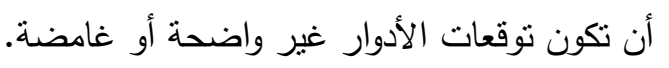

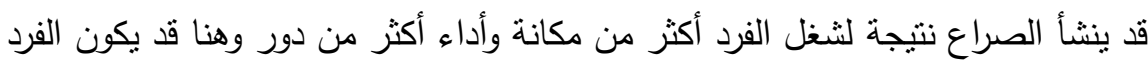
غير قادر على المواءمة بين كل هذه الأدوار التى يشغلها مما يجعله بعطى أكثر لدور معين على حساب آخر وهنا قد يحدث الصراع.

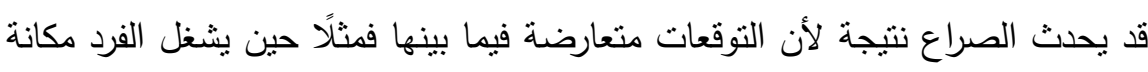

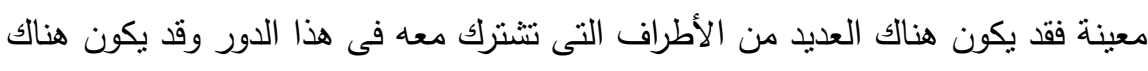
تعارض بين نوقعات بين كل هؤلاء المشتركين فى هذا الدور • (احسان زكى عبد هبد الغفار (آخرون،

\section{الاجبراءاهي المنهجية}

نوع الدراسة : دراسة وصفية تحليلية. منهج الاراسة: في سبيل تحقيق هدف الدراسة والاجابة على تساؤلاتها، اعتد الباحثون في هذه الدراسة على المنهج الوصفي التحليلي لجمع البيانات اللازمة لاتمام الدراسة.

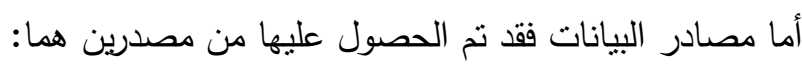

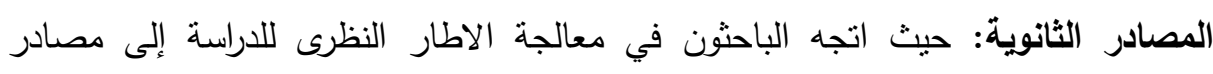
البيانات الثانوية والتى تتمنل في الكتب والمراجع العربية والاجنبية ذات العلاقة والدوريات والمقالات والتقارير والأبحاث والمطالعة في مواقع الانترنت المختلفة. 
المصادر الأولية: وتتمتل في جمع البيانات الأولية ميدانيًا، وذلك من خلال استخدام مقياس نم تصميمه خصيصًا لهذا الغرض، ووزع على العينة لجمع البيانات المطلوبة. أدوات الدراسة: في اطار هذه الدراسة استعان الباحثون بمقياس (التكيف الاجتماعي للمرأة العاملة) من تصميمهم لهذا الغرض. وصف المقياس: تضمن المقياس سبعة محاور أساسية، تضمن الدحور الأول البيانات الثخصية، وقد تم نوزيع المقياس على طالبات الدبلومات المهنية وقد نبين أن العبارات ملائمة واللغة مفهومة ومرنبة حسب طبيعة الموضوع.

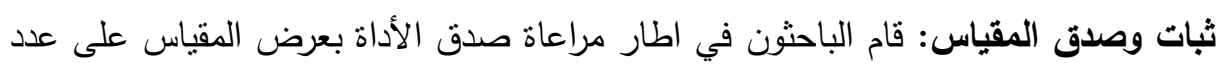

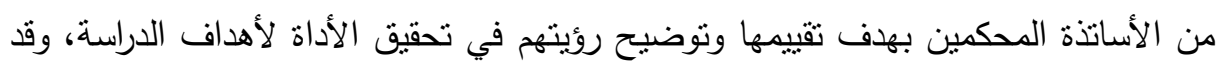

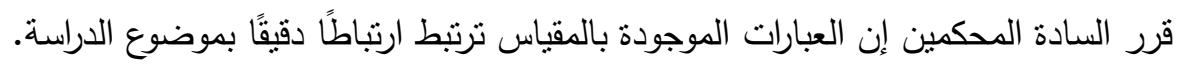
جدول (1 ): ثبات وصدق عبارات المقياس

\begin{tabular}{|c|c|c|c|c|}
\hline المعنوية & معامل ارتباط & قيمة ألفا & عدد العبارات & أبعاد المقياس الكلي \\
\hline$\cdot, \cdots 1$ & $\cdot$, , 0. & $\cdot, \vee \vee 9$ & 1. & الأدوار المتعددة للعاملة التى \\
\hline.,$\cdots 1$ & $\cdot$, OYo & $\cdot, 7 r 9$ & 1. & مظاهر صراع الأدوار \\
\hline$\cdot, \cdots 1$ & $\cdot, \vee \wedge \wedge$ & ד • • & 10 & المشكلات الاجتماعية والنفسية التى لتعرض لهاملة \\
\hline$\cdot, \cdots 1$ & • & $\cdot, \times 01$ & 1 . & تأثثر استكمال الدراسة على \\
\hline$\cdot, \cdots 1$ & $\cdot, \wedge Y$ & $\cdot, \wedge \vee \leq$ & 11 & آليات مواجهة المشكلات التى تلعرض لهاملة العاملة \\
\hline & & $\cdot, \vee \leqslant \leqslant \wedge$ & ov & إجمالي الاستبيان \\
\hline
\end{tabular}

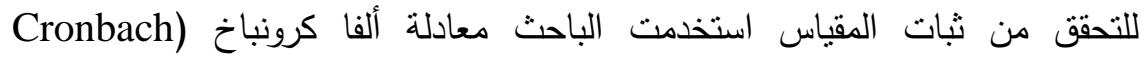
Alpha ق




العاملة، تأثثر استكمال الدراسة على شخصية العاملة، آليات مواجهة المشكلات التى تتعرض

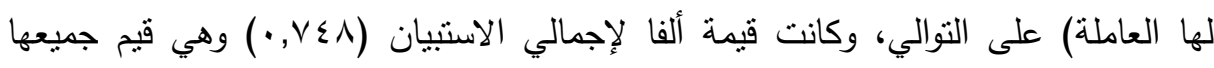

$$
\text { تؤكد على ثبات المقياس لكونها أعلى من (0, • •). }
$$

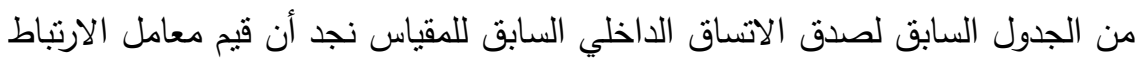

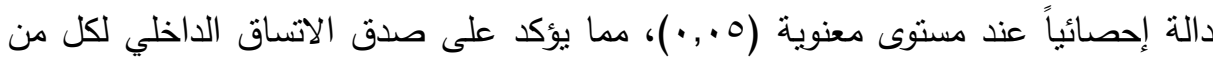

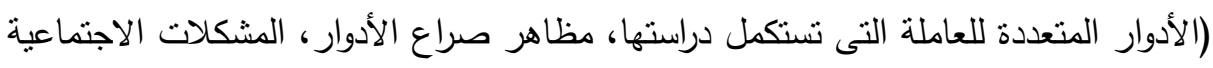


مواجهة المشكلات التى تتعرض لها العاملة) على التوالي وبلغت قيمتي معامل الإرتباط

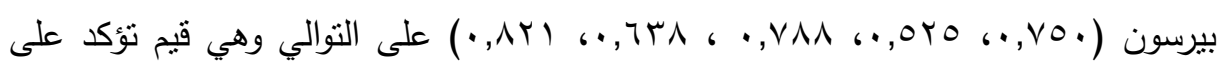
صدق المقياس.

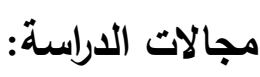
المجال البشري: عينة مكونة من الج مفردة من طالبات الدبلومات المهنية بمركز التعلم المدمج بجامعة عين شمس وتم اختيارها عدية.

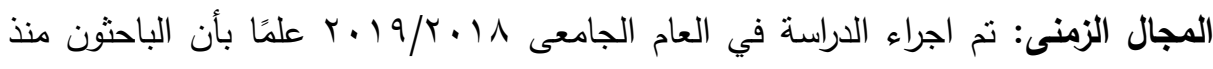

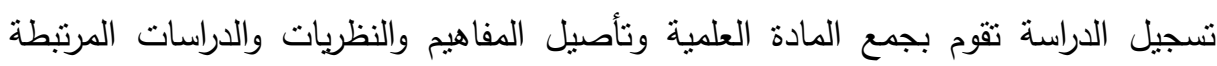
بموضوع البحث، و فترة جمع التراث النظرى للاراسة حتى تقوم على أسس موضوعية. المجال المكانى: مركز التعلم المدمج جامعة عين شمس.

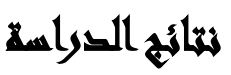

وصف وتحليل وتفسير نتائج الدراسة الميدانية: بعد جمع قوائم المقياس ومراجعتها، واستبعاد غير الصالحة منها قام الباحثون بادخال البيانات الحاسب الآلي، وقد استعان الباحثون بالأساليب الاحصائية التالية: 
تم تفريغ البيانات عن طريق البرنامج الإحصائي المعروف برنامج الحزم الإحصائية

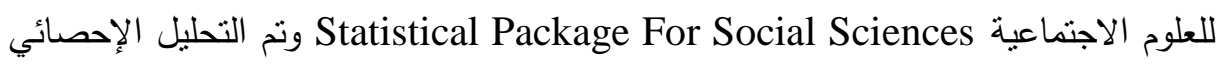

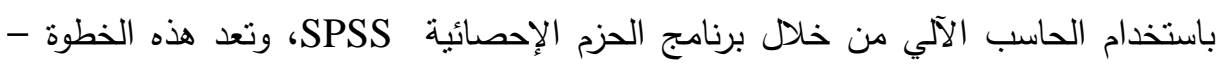

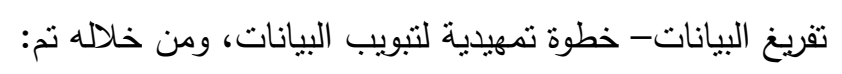
• • • ل التكرارات البسيطة والنسب المئوية.

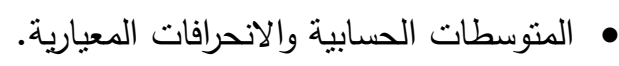

• الوزن المرجح الذي يحسب بضرب التكرارات بوزن معين بناء علي عدد المراتب في

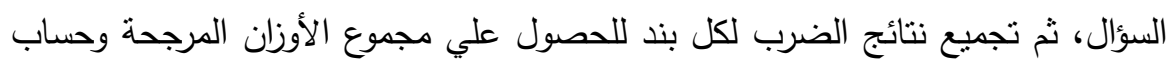
النسب المئوية لبنود السؤال. • اختبار كاr (Chi Square Test) لدراسة الدلالة الإحصائية للعلاقة بين متغيرين من المتغيرات الاسمية (Nominal). • معامل ارتباط بيرسون (Pearson Correlation Coefficient) لدراسة شدة واتجاه العلاقة الارتباطية بين متغيرين من نوع الفئة أو النسبة (Interval Or Ratio) وقد بدأد

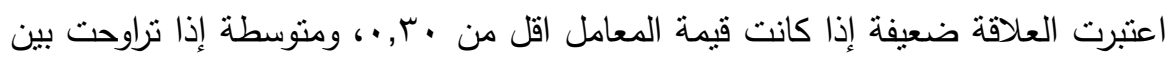

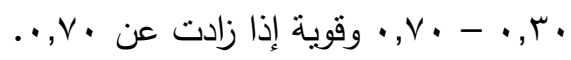
• اختبار (T- Test) لدراسة الدلالة الإحصائية للفروق بين المنتوسطات الحسابية لمجموعتين من المبحوثين في احد متغيرات الفئة أو النسبة (Interval Or Ratio).

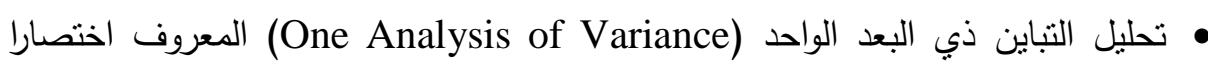
باسم ANOVA لدراسة الدلالة الإحصائية للفروق بين المتوسطات الحسابية لأكثر من مجموعتن من المبحوثين في احد متغيرات الفئة أو النسبة (Interval Or Ratio). 


\section{نتائج التحليل الإحصائي لإبعاد مقياس التكيف الاجتماعى للمرأة العاملة:}

جدول (Y): يوضح توزيع أبعاد المقياس وفقًا للحالة الاجتماعية للمرأة

\begin{tabular}{|c|c|c|c|c|c|c|}
\hline المعنوية & قيمة (ت) & الانحراف & المتوسط & العدد & 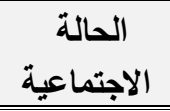 & \\
\hline \multirow{2}{*}{$\cdot, \cdots 1$} & \multirow{2}{*}{$r, \varepsilon) V$} & $r, I V T \leq$ & Yr,NI & $\leqslant \wedge$ & متزوجة & \multirow{2}{*}{ اللتى تنتكمل دراستها التعددة للعاملة } \\
\hline & & $7, \leqslant \wedge \wedge 70$ & $1 \wedge, \leqslant 7$ & 15 & غير منزوجة & \\
\hline \multirow{2}{*}{$\cdot,, \cdot r$} & \multirow{2}{*}{ r,IrV } & 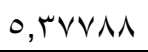 & $|\wedge, \wedge|$ & $\varepsilon \wedge$ & متزوجة & \multirow{2}{*}{ مظاهر صراع الأدوار } \\
\hline & & $\varepsilon, 0041$ & 15,79 & 14 & غير منزوجة & \\
\hline \multirow{2}{*}{$\cdot, \cdot \varepsilon$} & \multirow{2}{*}{$r, \ldots q$} & 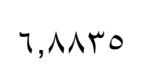 & rT, & $\varepsilon \wedge$ & متزوجة & \multirow{2}{*}{ النشكلات الاجتماعية التى تلعرض العاملة } \\
\hline & & 9,1 YAV & rq & $1 T$ & غير متزوجة & \\
\hline \multirow{2}{*}{$\cdot, 7$} & \multirow{2}{*}{$\cdot, \leq 77$} & r,OVAᄉ & $Y Y, \varepsilon V$ & $\varepsilon \wedge$ & متزوجة & \multirow{2}{*}{ تأثير شتنكمال الدراسة } \\
\hline & & $7,01 V Y$ & $Y, 1, \wedge \leq$ & $1 \pi$ & غير متزوجة & \\
\hline \multirow[b]{2}{*}{$\cdot, \cdots r$} & \multirow[b]{2}{*}{ T,TY } & r,Vqr人 & $r r, \wedge q$ & $\varepsilon \wedge$ & متزوجة & \multirow{2}{*}{ 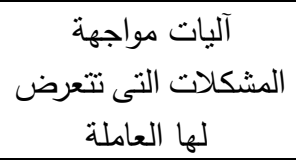 } \\
\hline & & $T, \cdot Y I T$ & $19, \pi \wedge$ & 14 & غير متزوجة & \\
\hline \multirow{2}{*}{$\cdot, \cdots 1$} & \multirow{2}{*}{$r, q \leq 0$} & Ir,VAr & $|Y|, 7$ & $\varepsilon \wedge$ & منزوجة & \multirow{2}{*}{ اجمالي } \\
\hline & & YI,TYI & $1 \cdot r, r$ & 15 & غير منزوجة & \\
\hline
\end{tabular}

يتضح من الجدول السابق لنتائج اختبار (ت) لتوضيح الفروق بين المرأة العاملة (متزوجة وغير منزوجة) الآتى:

() وجود فروق ذات دلالة إحصائية عند مستوى معنوية اقل من (0. . •) بين المرأة العاملة

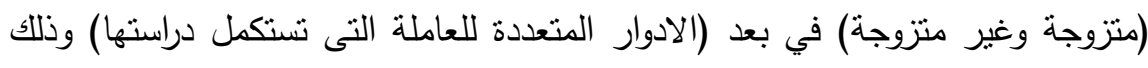

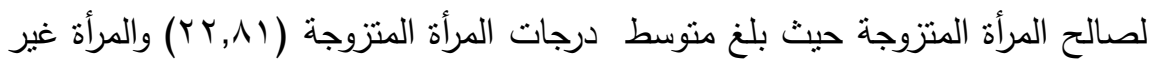

$$
\text { المتزوجة (1) (1) (1). }
$$

r) وجود فروق ذات دلالة إحصائية عند مستوى معنوية اقل من (0. . •) بين المرأة العاملة (متزوجة وغير متزوجة) في بعد (مظاهر صراع الأدوار) وذللك لصالح المرأه المتزوجة

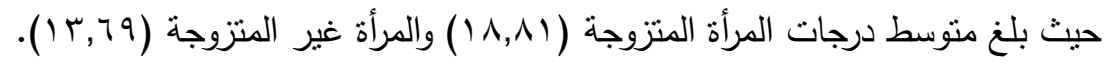


r) وجود فروق ذات دلالة إحصائية عند مستوى معنوية اقل من (0.,.•) بين المرأة العاملة

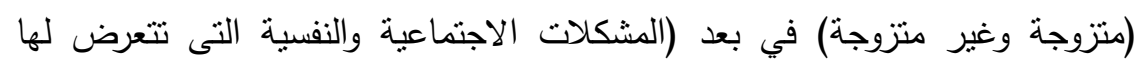

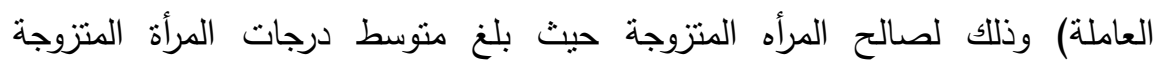

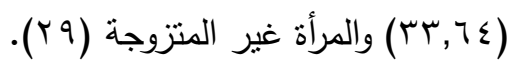

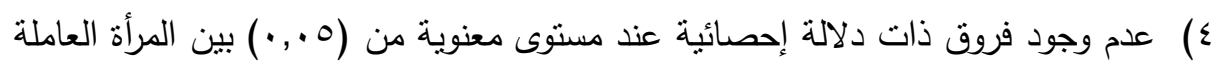
(متزوجة وغير متزوجة) في بعد (تأثير استكمال الدراسة على شخصية العاملة). 0) وجود فروق ذات دلالة إحصائية عند مستوى معنوية اقل من (0.., •) بين المرأة العاملة

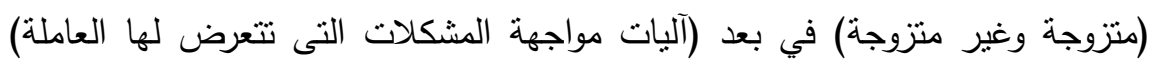

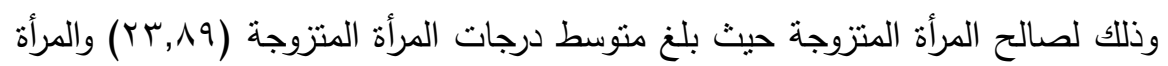

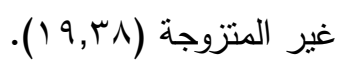
7) وجود فروق ذات دلالة إحصائية عند مستوى معنوية اقل من (0., •) بين المرأة العاملة

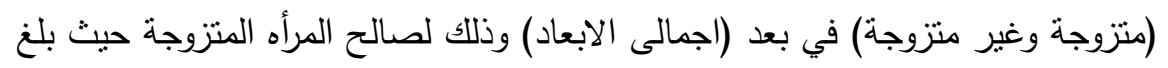

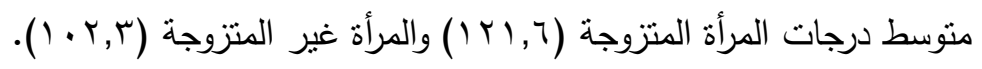


مجلة العلوم البيئية

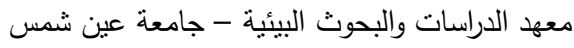

جدول (r): يوضح توزيع أبعاد المقياس وفقًا لمتغير عمر المرأة

\begin{tabular}{|c|c|c|c|c|c|c|}
\hline مستوية & قيمة & الانحراف & الحستوسط & العدد & العمر & \\
\hline \multirow{3}{*}{$\cdot, \cdot r$} & \multirow{3}{*}{$\Gamma, \uparrow \wedge \vee$} & $r, r \cdots q$ & rT,VTIq & rI & من.r-r.r & \multirow{3}{*}{ الادوار المتعددة للعاملة } \\
\hline & & 0,7117 & $r \cdot, r_{T}$ & ro & من. r- . ؛ & \\
\hline & & $r, 1 \leq \varepsilon 17$ & $r I, \Lambda$ & 10 & من. - - & \\
\hline \multirow{3}{*}{$\cdot, r$} & \multirow{3}{*}{$1, \wedge 74$} & $Y, V I Y \wedge Y$ & 19,0YTA & rI & من.r-r.r & \multirow{3}{*}{ مظاهر صراع الأدوار } \\
\hline & & 0,70710 & $17, \varepsilon$ & ro & من.r- •. & \\
\hline & & r,O^०TV & $\mid V, \varepsilon$ & 10 & من. ع- & \\
\hline \multirow{3}{*}{ • } & \multirow{3}{*}{$1,1 \cdot 1$} & $0, \pi V_{1}$ & וניז, & YI & من •r-.r & \multirow{3}{*}{ والنفسية التى تتعرضلات الاجتماعية لها } \\
\hline & & $9,790 \mathrm{~V}$ & Tr,0T & ro & من •r-" & \\
\hline & & $0,9 \cdot r \mu \wedge$ & אسזו,.•r & 10 & من.ع-. & \\
\hline \multirow{3}{*}{$\cdot, 0$} & \multirow{3}{*}{$\cdot, 7 \leqslant 9$} & $r, \varepsilon .0 \wedge \Lambda$ & Tr & rI & من.r-r.r & \multirow{3}{*}{ تأثير استكمال الدراسة } \\
\hline & & $0, \leqslant 0 \leqslant \mu \uparrow$ & $r_{1,7}$ & ro & من •r-. & \\
\hline & & $r, Y Y \backslash 90$ & YY,TTTV & 10 & من . ع- 0. & \\
\hline \multirow{3}{*}{$\cdot, \cdot r$} & \multirow{3}{*}{, 107} & $\varepsilon, \cdot 1 \cdot 10$ & $r \varepsilon, \Gamma \wedge)$ & $r 1$ & من.r-r.r & \multirow{3}{*}{ التى تتعرض لهواجهة المشكلات العاملة } \\
\hline & & 0, TOVAT & $r \cdot, 97$ & ro & من.r- & \\
\hline & & r, voro & $r \leqslant, r$ & 10 & من. ع- 0 & \\
\hline \multirow{3}{*}{$\cdot, \cdot \wedge$} & \multirow{3}{*}{ r,OH } & $1 \leq, 09710$ & $\mid Y \varepsilon, \cdot \varepsilon V$ & $r_{1}$ & من • Y-. & \multirow{3}{*}{ اجمالي } \\
\hline & & $r,, r \cdot r \cdot \varepsilon$ & $\| r, \wedge \Lambda$ & ro & من .r-, ــ & \\
\hline & & $1 ., 9 \pi \pi 11$ & $117, r$ & 10 & من .ع- 0. & \\
\hline
\end{tabular}

يتضح من الجدول السابق لنتائج اختبار (ف) لتوضيح الفروق بين( العمر) وأبعاد الدراسة الآتي:

() عدم وجود فروق ذات دلالة إحصائية عند مستوى معنوية من (0., •) بين عمر المرأة

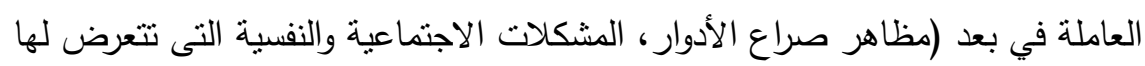

العاملة، تأثير استكمال الدراسة على شخصية العاملة). 
r) وجود فروق ذات دلالة إحصائية عند مسنوى معنوية اقل من (0., •) بين عمر المرأة

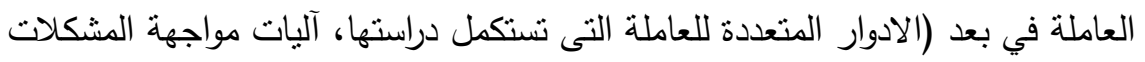
التى تتعرض لها العاملة).

جدول ( ) ): يوضح نوزيع أبعاد المقياس وفقًا لمتغير وظيفة المرأة

\begin{tabular}{|c|c|c|c|c|c|c|}
\hline المغنوية & قيمة & الانحراف & المستوسط & العدد & الوظيفة & \\
\hline \multirow{4}{*}{$\cdot, \cdot r$} & \multirow{4}{*}{$r, 110$} & $r, \cdot q \wedge r q$ & $r T, Y$ & 10 & محاسبة & \multirow{4}{*}{ تلادنكاملة التتعددة } \\
\hline & & T, YVYTV & $19, r M \cdot \Lambda$ & 14 & مهندسة & \\
\hline & & $r, \cdot\{\lambda 1$ & $r r, q . q 1$ & 11 & طبيبة & \\
\hline & & 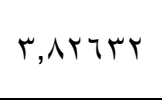 & Y $1,0 \leq 00$ & rr & خدمة عملاء & \\
\hline \multirow{4}{*}{$\cdot, r$} & \multirow{4}{*}{$1,7 \cdot 7$} & $1, \cdot 7, \leq 9$ & 19,7 & 10 & محاسبة & \multirow{4}{*}{ مظاهر صراع } \\
\hline & & $\varepsilon, 10$ Yos & $10, . \times 79$ & $1 \pi$ & مرندسة & \\
\hline & & r,V7471 & IV,7ז & 11 & طبيية & \\
\hline & & $0, .0771$ & $11, \cdot \leq 00$ & rT & خدمة عملاء & \\
\hline \multirow{4}{*}{$\cdot, 9$} & \multirow{4}{*}{$\cdot, \cdot r$} & $0,0 Y V \leqslant Y$ & TY, \&TTV & 10 & محاسبة & \multirow{4}{*}{ 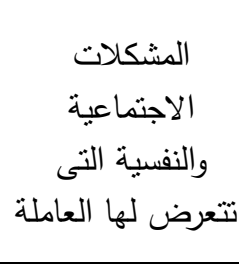 } \\
\hline & & $9, \leq \leqslant 1 \leq 0$ & $r Y, \wedge \leq T r$ & Ir & مهندسة & \\
\hline & & $V, 07 \leqslant Y V$ & Tr,YVTV & 11 & طبيبة & \\
\hline & & 1., $9.0 r$ & דr,גזr & rr & خدمة عملاء & \\
\hline \multirow{4}{*}{$\cdot, r$} & \multirow{4}{*}{$1,7 r v$} & $r, \varepsilon \wedge 1 q r$ & זrתוסותז & 10 & محاسبة & \multirow{4}{*}{ شخصية العاملة الثني } \\
\hline & & $0, \cdot r \cdot 71$ & $r \cdot, 10 r \wedge$ & $1 \pi$ & مرندسة & \\
\hline & & $r, \cdot v \leq \wedge r$ & דזדצזיזי & 11 & طبيبة & \\
\hline & & $\varepsilon, 7 \vee \uparrow 00$ & $r Y, \wedge \backslash \wedge r$ & rr & خذمة عملاء & \\
\hline
\end{tabular}


مجلة العلوم البيئية

معهد الدراسات والبحوث البيئة - جامعة عين شمس لئس

\begin{tabular}{|c|c|c|c|c|c|c|}
\hline مستوية & قيمة & الانحراف & الحسابي & العدد & الوظيفة & \\
\hline \multirow{4}{*}{$\cdot, r$} & \multirow{4}{*}{ 1, } & $r, \Sigma \wedge \mid q r$ & זrתום, & 10 & محاسبة & \multirow{4}{*}{ شخصية الثاسثة استكمال } \\
\hline & & $0, \cdot r \cdot T \Lambda$ & r.,10r & $1 \pi$ & مهندسة & \\
\hline & & $r, \cdot V \leqslant \wedge r$ & צrדותיזי & 11 & طبيبة & \\
\hline & & $\varepsilon, 7 \vee 700$ & $r Y, \wedge \backslash \wedge r$ & rr & خدمة عملاء & \\
\hline \multirow{4}{*}{$\cdot, \Sigma$} & \multirow{4}{*}{$1, .7$} & $r, 0 \leqslant r q r$ & $r \varepsilon, \varepsilon 77 V$ & 10 & محاسبة & \multirow{4}{*}{ آلتعرض آليات مواجهة التها العاملة } \\
\hline & & $7, r) T \leq \varepsilon$ & $r,, r \cdot V V$ & $1 T$ & مهندسة & \\
\hline & & $\varepsilon, \Gamma 7941$ & $r r, 9.91$ & 11 & طبيية & \\
\hline & & $\varepsilon, \Gamma \wedge ৭ r \mu$ & דrד,גיו & rr & خدمة عملاء & \\
\hline \multirow{4}{*}{$\cdot, r$} & \multirow{4}{*}{$1, \vee \wedge T$} & $10,0 \leq \cdot 1\}$ & צד,Yצו & 10 & محاسبة & \multirow{4}{*}{ اجمالي } \\
\hline & & rr, & $1 \cdot 1,710$ & 14 & مهندسة & \\
\hline & & $\mid r, Y 0117$ & $119, .9$. & 11 & طبيية & \\
\hline & & $10, \leqslant V V \leq V$ & דr|11 & rr & خدمة عملاء & \\
\hline
\end{tabular}

يتضح من الجدول السابق لنتائج اختبار (ف) بين (وظيفة المرأة العاملة) وأبعاد الدراسة ما بلي:

عدم وجود فروق ذات دلالة إحصائية عند مستوى معنوية من (0., •) بين وظيفة المرأة

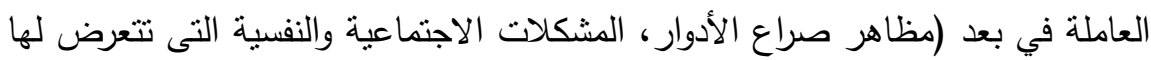
العاملة، تأثثر استكمال الدراسة على شخصبة العاملة، آليات مواجهة المشكلات التى تتعرض لها العاملة). وجود فروق ذات دلالة إحصائية عند مستوى معنوية اقل من (ه.,.•) بين وظيفة المرأة العاملة في بعد (الادوار المتعددة للعاملة التى تستكمل دراستها). 


\section{النتائج المتعلقة بتساؤلات الاراسة:}

النتائج المتعلة بالتساؤل الأول: ما الأدوار التى تقوم بها المرأة العاملة التى تستكل

تتعدد الأدوار المنوطة بالمرأة العاملة التي تشتكمل دراستها وثأنى في مقدنها مثابعة

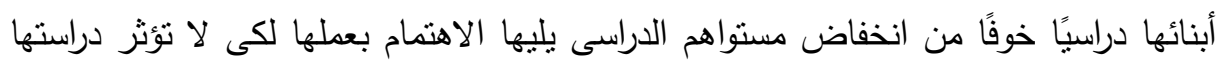

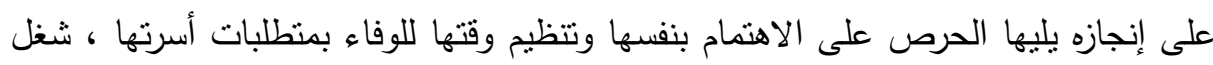

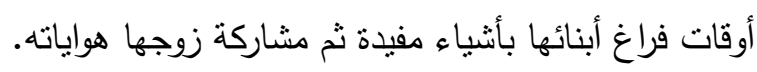

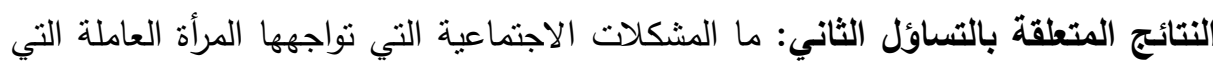

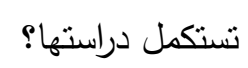

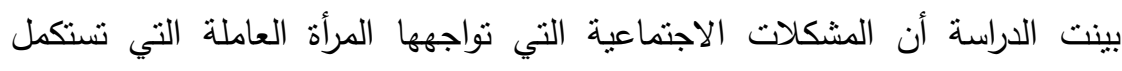

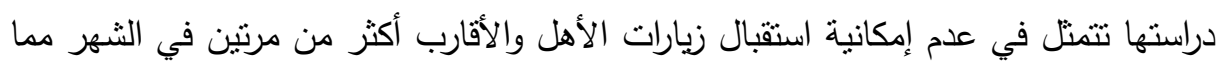

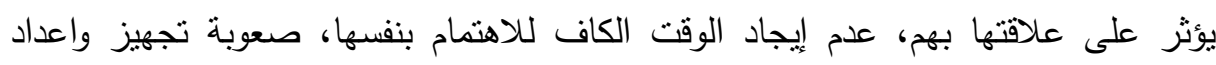

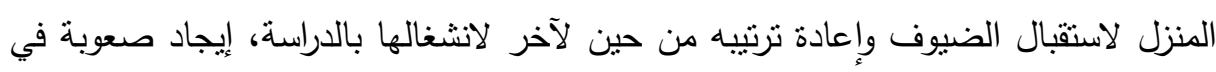

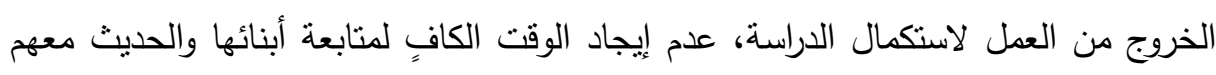

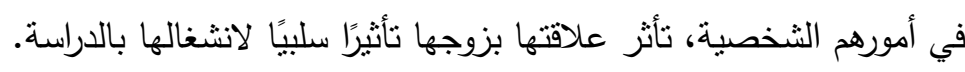

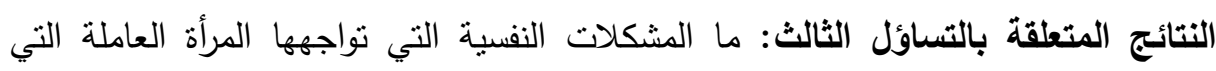

$$
\text { تستكمل دراستها؟ }
$$

تعرض المرأة العاملة التي تستكمل دراستها للضغط النفسي الثنديد والقلق بسبب كثرة

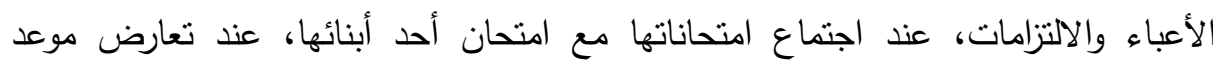

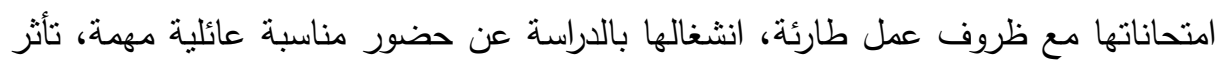

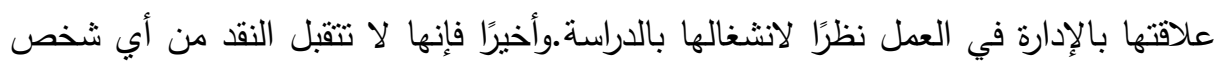

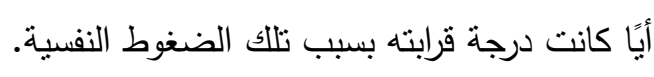
النتائج المتعقة بالتساؤل الرابع: ما الآليات التى تمكن المرأة من مواجهة مشكلات استكمال الدراسة؟ العنج 
بينت الدراسة أن الآليات التي تمكن المرأة من مواجهة مشكلات استكمال الدراسة تتمثل

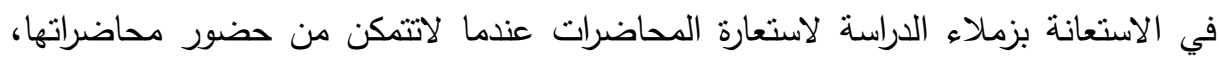
تقضى وقت إضافى في عملها لحل مشكلة خروجها من العمل، الاستعانة بمساعدة أبنائها في

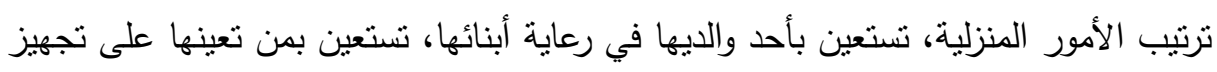

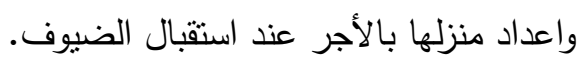

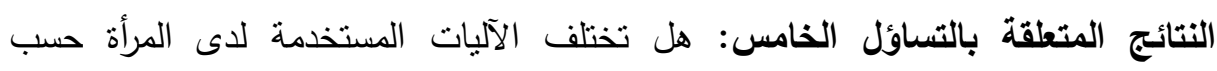
المتغيرات التالية: السن، الحالة الاجتماعية، الوظيفة؟ بالئج وجود فروق ذات دلالة إحصائية عند مستوى معنوية اقل من (0. . • ) بين المرأة العاملة (متزوجة وغير متزوجة) في بعد (آليات مواجهة المشكلات التى تتعرض لهاتيه لها العاملة) وذللك لصالح المرأة المتزوجة.

وجود فروق ذات دلالة إحصائية عند مستوى معنوية اقل من (0. . •) بين عمر المرأة

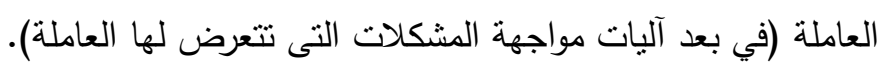
عدم وجود فروق ذات دلالة إحصائية عند مستوى معنوية من (0. . . •) بين وظيفة المرأة العاملة في بعد ( آليات مواجهة المشكلات التى تتعرض لها داتهاته دلعاملة).

\section{تمصيامت الصواسمة}

إنشاء دور الحضانة للأطفال الرضع والصغار فى سائر المصانع والمؤسسات حتى العى تطمئن الأم العاملة على طفلها وقت وجودها فى العمل وتتمكن من قيامها بدورها

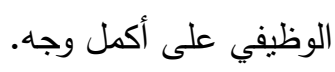

استبعاد التمييز على أساس النوع، والاعتراف بتعدد أدوار المرأة باعتبارها مشاركة للرجل

$$
\text { وليست منفصلة عنه. }
$$

إتقان العمل الذى تقوم به لتجنب مضايقة مديرين العمل ويصبح إهمالها سبب لتهميشها

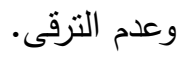

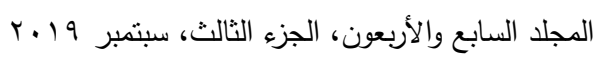




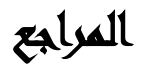

ابراهيم عبد الرحمن رجب وآخرون (r/911): نماذج ونظريات نتظيم المجتمع، القاهرة، دار النقافة للطباعة والنشر .

احسان زكى عبد الغفار وآخرون (r · . r): الاتجاهات الحديثة فى خدمة الفرد، مكتبة جامعة حلوان.

أحمد زايد (Y . . Y): صور من الخطاب الديني المعاصر ، القاهرة، مكتبة الأنجلو المصرية.

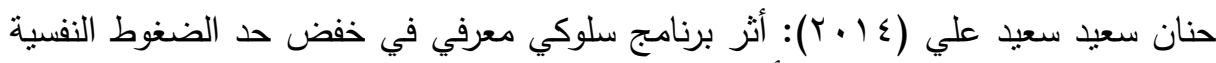

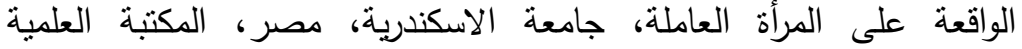

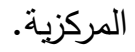

داليا محمد أحمد عمارة (10 ب ب): ضغوط الحياة اليومية على المرأة وأثرها على التكيف البيئي



$$
\text { والبحوث البيئية، جامعة عين شمس. }
$$

سامية الساعاتي ( ( . ب): الثقافة والثخصية، بحث علم الاجتماع الثقافى، دار الفكر العربى.

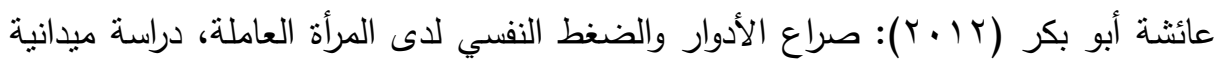

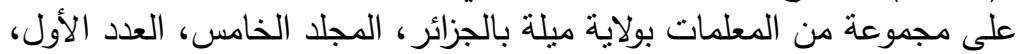
مجلة جامعة أم القرى للعلوم الاجتماعية.

ماجي الحلواني: رؤية مستقبلية لبرامج المرأة في المنتدى الفكرى الأول للمجلس القومى اللمى للمرأة

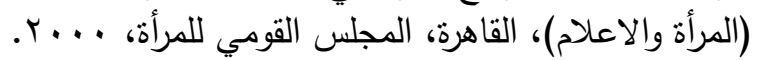

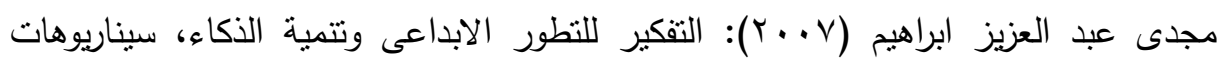
تربوية مقترحة، القاهرة، عالم الكتب.

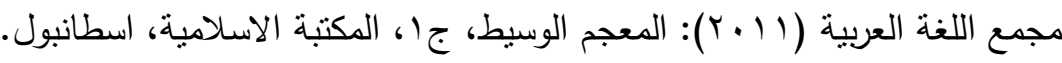

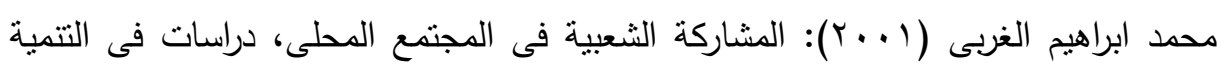
الريفية، قسم المجتمع الريفى، كلية الزراعة، جامعة المعائ الاسكندرية.

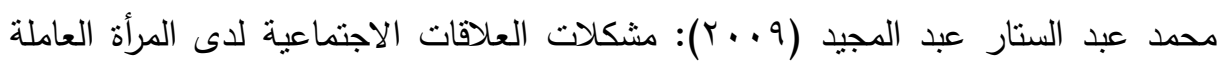

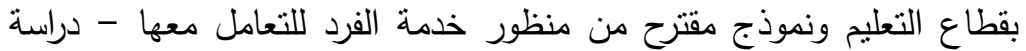
وصفية مطبقة على إدارة قنا التعليمية، رسالة ماجسنير (غير منئنة منشورة)، كلية الخدمة الاجتماعية، جامعة حلوان. 
Alan Booth, Women outside Employment and Marital Instability, American Journal of aociology, volume go ,No.30, (November 1984).

Holiander, E. P.: Leadership Dynamics: A practical Guide To Effective Relationship, NewYork, Free Press, 1978.

Tasnim, M.; Hossain, M. Z. and Enam, Work-Life Balance: Reality Check for Working Women of Bangladesh. Journal of Human Resource, 2017.

\title{
MECHANISMS OF WORKING WOMEN COEXISTING WITH THE PROBLEMS OF COMPLETING THEIR STUDIES
}

Marwa M. Hosny ${ }^{(1)}$; Eglal I. Helmy ${ }^{(2)}$; Ahmed A. Mohamed ${ }^{(3)}$ Al Shimaa B. Amer ${ }^{(4)}$

1) Blanded Learning Center, Ain Shams University 2) Faculty of Arts, Ain Shams University 3) Studies \& Field and Social Surveys, The Arab League 4) Institute Of Environmental Studies and Researsh, Ain-Shams University

\begin{abstract}
The study aimed to identify the problems faced by working women in the case of completing their studies and identify the means and mechanisms used by women to face those problems so as not to accumulate with each other, which increases the severity of the problems and exacerbated, which is difficult to deal with later. To achieve this goal, the researchers relied on theoretical rooting through the inductive method of books, references and Arabic and foreign studies.
\end{abstract}

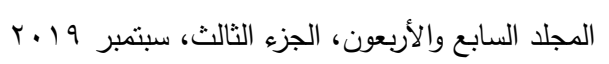


The study applied to a sample of 61 female students of vocational diplomas in the integrated learning center, Ain Shams University. This study belongs to the descriptive studies, and the statistical analysis of the data using SPSS, the researchers used theories of social role, functional constructivism, role conflict.

The study reached the following important results: There are many roles assigned to working women who complete their studies. The most important of these is the follow-up of their sons, fearing their low level of study, followed by interest in their work so that their studies will not affect their achievement his hobbies. The working woman who completes her studies suffers from a conflict of roles in her attempt to reconcile the home, work and study. The study showed that the social problems faced by working women who complete their studies are the inability to receive visits from parents and relatives more than twice a month, which affects their relationship, lack of time enough to take care of themselves, difficulty preparing the house to receive guests and rearrange from time to time because of her preoccupation with the study, finding it difficult to get out of work to complete the study, not finding enough time to follow up her children and talk with them about their personal matters, her relationship was affected negatively by her preoccupation with the study.

The study recommends that attention be given to women on a wider scale, and that the society's negative perception of the idea of completing its study should be changed alongside its work and that some misconceptions about the husband and the elderly be reversed. 